\title{
Development and Validation of Ultra Performance Liquid Chromatographic Method for the Simultaneous Estimation of Lamivudine, Tenofovir Disoproxil Fumarate, Doravirine and Efavirenz in Bulk and Pharmaceutical Formulations
}

\author{
PRASANTHI CHENGALVA* AND MADHAVI KUCHANA ${ }^{1}$ \\ Department of Pharmaceutical Analysis, Annamacharya College of Pharmacy, Rajampet 516126, ${ }^{1}$ Institute of Pharmaceutical \\ Technology, Sri Padmavati Mahila Visvavidyalayam (Women's University), Tirupati 517502, India
}

Chengalva et al.: UPLC Estimation of Lamivudine, Tenofovir Disoproxil Fumarate, Doravirine and Efavirenz

\begin{abstract}
A simple and rapid stability indicating reverse phase ultra-performance liquid chromatographic method has been established and validated for the simultaneous quantification of lamivudine, tenofovir disoproxil fumarate, doravirine and efavirenz in bulk and pharmaceutical formulations. The chromatographic separation was performed on Acquity Ethylene Bridged Hybrid Phenyl $(50 \mathrm{~mm} \times 2.1 \mathrm{~mm}, 1.7 \mu \mathrm{m})$ column. The isocratic elution system of water and acetonitrile in the ratio 50:50 v/v pumped at a flow rate $0.4 \mathrm{ml} / \mathrm{min}$ in isocratic mode. The injection volume set was $1 \mu \mathrm{l}$ and the detection wavelength was $238 \mathrm{~nm}$. The column temperature was set at $30^{\circ}$. The retention times of lamivudine, tenofovir disoproxil fumarate, doravirine and efavirenz were found to be $1.012 \mathrm{~min}, 1.233 \mathrm{~min}, 1.428 \mathrm{~min}$ and $1.666 \mathrm{~min}$ respectively with a total run time of $3 \mathrm{~min}$. The proposed method was validated according to International Council on Harmonisation Q2 (R1) guidelines. The percentage recoveries were found to be in the range of 99.56 $\mathbf{- 1 0 0 . 4 0 \%} \%$. The relative standard deviation values obtained during precision studies were found to be less than 2. Linearity between concentration and response was found within the specified concentration range and the correlation coefficient was found to be 0.999 for all the drugs. Degradation studies were carried out under various stress conditions such as acid, base, oxidation, heat and light and found no interference of degraded impurity peaks at the retention time of analyte peaks. Hence, the proposed ultra-performance liquid chromatographic method can be utilized in the routine quality investigation of lamivudine, tenofovir disoproxil fumarate, doravirine and efavirenz either individually or simultaneously in bulk and co-formulated dosage forms.
\end{abstract}

Key words: Lamivudine, tenofovir disoproxil fumarate, doravirine, efavirenz, reverse phase ultraperformance liquid chromatographic method, method development and validation

Antiretroviral drugs are used for the treatment of retroviral infection, primarily human immune virus (HIV). Combinational therapy of antiretroviral drugs is preferred for highly active treatment. Antiretroviral drug molecules such as lamivudine, tenofovir disoproxil fumarate, doravirine and efavirenz were selected for the study, as these are the drugs among most commonly prescribed for HIV therapy. Lamivudine (fig. 1A) is chemically 4-amino-1-[(2R,5S)-2-(hydroxymethyl)1,3-oxathiolan-5-yl]pyrimidin-2-one. It is formulated as tablets and oral solution. Tenofovir disoproxil fumarate (fig. $1 \mathrm{~B})$ is $\{[(2 \mathrm{R})-1-(6-$ aminopurin-9-yl)propan-2yl]oxymethyl-(propan-2-yloxycarbonyloxymethoxy) phosphoryl\}oxymethylpropan-2-yl carbonate;(E)-but-

*Address for correspondence

E-mail: prashanthi.chengalva87@gmail.com

November-December 2020

Indian Journal of Pharmaceutical Sciences 2-enedioic acid. Doravirine (fig. 1C) is 3-chloro-5( $\{1-[(4-m$ ethyl-5-ox o-4,5-dihydro-1 H-1,2,4triazol-3-yl)methyl]-2-oxo-4-(trifluoromethyl)-1,2dihydropyridin-3-yl\} oxy)benzonitrile. Efavirenz (fig. 1D) is (4S)-6-chloro-4-(2-cyclopropylethynyl)-4(trifluoromethyl)-2,4-dihydro-1H-3,1-benzoxazin2-one. These are the drugs that belong to the class of reverse transcriptase inhibitors. They are available

This is an open access article distributed under the terms of the Creative Commons Attribution-NonCommercial-ShareAlike 3.0 License, which allows others to remix, tweak, and build upon the work non-commercially, as long as the author is credited and the new creations are licensed under the identical terms

Accepted 23 December 2020

Revised 16 September 2020

Received 27 April 2020

Indian J Pharm Sci 2020;82(6):1006-1014 


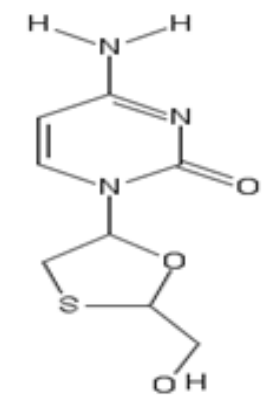

A

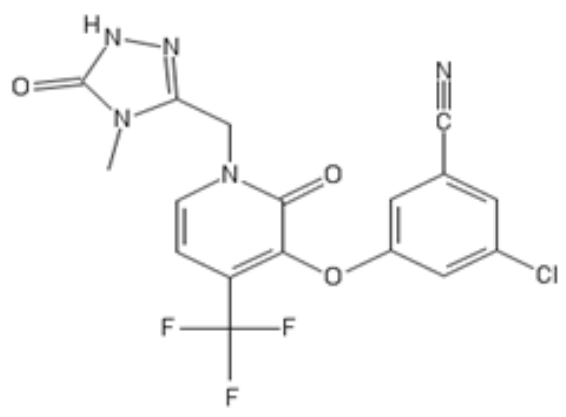

C

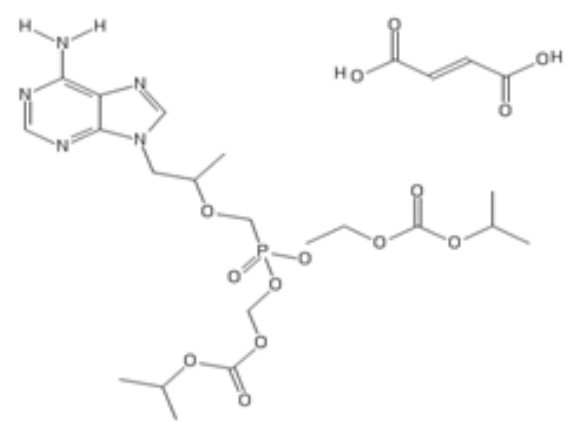

B

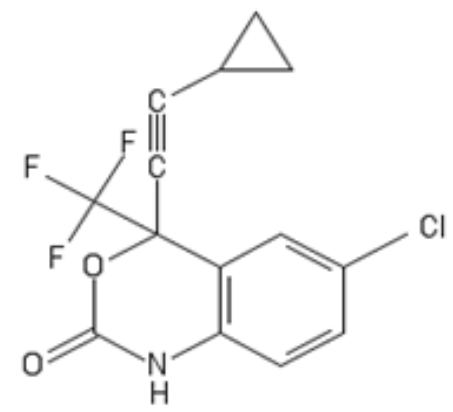

D

Fig. 1: Structure of analytes. Structures of A. lamivudine, B. tenofovir disoproxil fumarate, C. doravirine and D. efavirenz

as single drug formulations with varied strengths and also as co-formulated dosage forms with other HIV drugs used in the effective management of retro viral infections and Hepatitis B. A combination of lamivudine, tenofovir disoproxil fumarate and efavirenz tablets are available in the market with different trade names such as Trioday, Vonaday and Telura by various manufacturers. Lamivudine and tenofovir disoproxil fumarate with doravirine combinational tablets are available with the trade name Delstrigo. An extensive literature survey revealed analytical methods for the estimation of specified drugs individually ${ }^{[1,2]}$ and also in combination with other drugs ${ }^{[3-5]}$. An ultraperformance liquid chromatography-tandem mass spectrometry (UPLC-MS/MS) method was reported for the impurities characterization of doravirine ${ }^{[6]}$. Few liquid chromatographic methods were reported for the simultaneous estimation of efavirenz along with impurities $^{[7,8]}$. There were simultaneous Reverse-phase high performance liquid chromatography (RP-HPLC) methods proposed for efavirenz in combination with lamivudine and tenofovir disoproxil fumarate ${ }^{[9-12]}$, but in those methods efavirenz has longer retention time
(RT) and the run time of the studies was high leading to longer analysis time. In addition to these, there was no ultra-performance liquid chromatography (UPLC) method yet reported for the simultaneous estimation of the proposed lamivudine, tenofovir disoproxil fumarate, doravirine and efavirenz. Henceforth, there is a scope for the development of a simple and fast method that can analyze all the four drugs either in single or combination formulations as well as in bulk. The present investigation depicts the development and validation of accurate and isocratic Reverse-phase ultra-performance liquid chromatography (RP-UPLC) method with excellent resolution for the assay of lamivudine, tenofovir disoproxil fumarate, doravirine and efavirenz. Therefore, this method can be used for the routine quality control of bulk and marketed formulations of selected drugs, utilizing a simple mobile phase in short time.

\section{MATERIALS AND METHODS}

Combinational tablets containing $300 \mathrm{mg}$ of lamivudine, $300 \mathrm{mg}$ of tenofovir disoproxil fumarate, $100 \mathrm{mg}$ of doravirine (formulation A) and the reference standards 
were procured from Spectrum Pharma Research Solutions, Hyderabad. Trioday tablets manufactured by Cipla (formulation B) were purchased from the local market. Acetonitrile and HPLC grade water of analytical grade from Merck Ltd., Mumbai. The diluent used was water and acetonitrile in the ratio of $50: 50 \mathrm{v} / \mathrm{v}$.

\section{Chromatographic conditions:}

The instrument used was Acquity UPLC H-Class system of Waters, Milford, USA. It consists of binary solvent manager, auto sampler and Ultraviolet (UV) detector. The output signal was monitored and processed using Empower software. Chromatographic separation was performed on Acquity Ethylene Bridged Hybrid (BEH) Phenyl column $(50 \mathrm{~mm} \times 2.1 \mathrm{~mm}$, $1.7 \mu \mathrm{m})$ with UV detection at $238 \mathrm{~nm}$. The mobile phase consisting of water and acetonitrile in the ratio $50: 50 \mathrm{v} / \mathrm{v}$ was pumped at a flow rate $0.4 \mathrm{ml} / \mathrm{min}$ in isocratic mode with an injection volume of $1 \mu \mathrm{l}$ and the column temperature was set at $30^{\circ}$.

\section{Preparation of standard solution:}

Accurately $7.5 \mathrm{mg}$ of lamivudine, $7.5 \mathrm{mg}$ of tenofovir disoproxil fumarate, $2.5 \mathrm{mg}$ of doravirine and $15 \mathrm{mg}$ of efavirenz were weighed, then transferred into a clean and dry $25 \mathrm{ml}$ volumetric flask. To this, $15 \mathrm{ml}$ of diluent was added, sonicated for $10 \mathrm{~min}$ and made up to the final volume with diluent. This was considered as the primary stock solution. From the primary stock, $1 \mathrm{ml}$ was taken into a $10 \mathrm{ml}$ volumetric flask and made up to the volume with diluent. This was considered as working standard solution with final concentrations of $30 \mu \mathrm{g} / \mathrm{ml}$ of lamivudine, $30 \mu \mathrm{g} / \mathrm{ml}$ of tenofovir disoproxil fumarate, $10 \mu \mathrm{g} / \mathrm{ml}$ of doravirine and $60 \mu \mathrm{g} / \mathrm{ml}$ of efavirenz.

\section{Sample solution preparation (Formulation A):}

Combinational tablets containing $300 \mathrm{mg}$ of lamivudine, $300 \mathrm{mg}$ of tenofovir disoproxil fumarate, $100 \mathrm{mg}$ of doravirine were taken for the sample solution preparation. Twenty tablets were grinded into fine powder in a mortar. From this, the weight of powder equivalent to $7.5 \mathrm{mg}$ of lamivudine, $7.5 \mathrm{mg}$ of tenofovir disoproxil fumarate, $2.5 \mathrm{mg}$ of doravirine was taken and transferred into $25 \mathrm{ml}$ clean dry volumetric flask, $15 \mathrm{ml}$ of diluent was added, sonicated for $15 \mathrm{~min}$, filtered and made up to the final volume with diluent. From the above solution, $1 \mathrm{ml}$ was taken into a $10 \mathrm{ml}$ volumetric flask and made up to the volume with diluent.

\section{Sample solution preparation (Formulation B):}

Trioday tablets were taken for the sample solution preparation. Twenty tablets were grinded into fine powder in a mortar. From this, the weight of powder equivalent to $7.5 \mathrm{mg}$ of lamivudine, $7.5 \mathrm{mg}$ of tenofovir disoproxil fumarate, $15 \mathrm{mg}$ of efavirenz was taken and transferred into $25 \mathrm{ml}$ clean dry volumetric flask, $15 \mathrm{ml}$ of diluent was added, sonicated for $15 \mathrm{~min}$, filtered and made up to the final volume with diluent. From the above solution, $1 \mathrm{ml}$ was taken into a $10 \mathrm{ml}$ volumetric flask and made up to the volume with diluent.

\section{Preparation of forced degradation samples:}

As a part of forced degradation studies, the sample of acid degradation was prepared by taking $1 \mathrm{ml}$ of standard stock solution and $1 \mathrm{ml}$ of 1 Normal $(1 \mathrm{~N})$ hydrochloric acid and refluxed for $30 \mathrm{~min}$ at $60^{\circ}$. After refluxing, the resultant solution was neutralized by adding $1 \mathrm{~N}$ sodium hydroxide solution and was diluted up to $10 \mathrm{ml}$ with diluent. The base degradation sample was prepared by taking $1 \mathrm{ml}$ of standard stock and $1 \mathrm{ml}$ of $1 \mathrm{~N}$ sodium hydroxide and refluxed for $30 \mathrm{~min}$ at $60^{\circ}$. After refluxing, the resultant solution was neutralized by adding $1 \mathrm{~N}$ hydrochloric acid solution and was diluted up to $10 \mathrm{ml}$ with diluent. During oxidative degradation, to $1 \mathrm{ml}$ of standard stock, $1 \mathrm{ml}$ of of $10 \%$ hydrogen peroxide was added and the resultant solution was kept undisturbed for $30 \mathrm{~min}$ at $60^{\circ}$, then the volume was made up to $10 \mathrm{ml}$ with diluent. During sample preparation of thermal degradation, the standard stock solution was kept in the oven at $60^{\circ}$ for $6 \mathrm{~h}$. From the resultant stock solution, $1 \mathrm{ml}$ was taken into $10 \mathrm{ml}$ volumetric flask and made up to the volume with diluent. As a part of the photo stability study, $10 \mathrm{ml}$ of stock solution was kept under UV light for $3 \mathrm{~d}$. From the resultant stock solution, $1 \mathrm{ml}$ was taken into a $10 \mathrm{ml}$ volumetric flask and made up to the volume with diluent ${ }^{[13]}$.

\section{Method development:}

Varied chromatographic conditions were tried to get sharp peaks with good resolution and for rapid elution. Different combinations of solvents in different ratios as mobile phase were examined and found that the suitable mobile phase for the separation was water and acetonitrile in the ratio of 50:50 v/v. It was pumped at a flow rate of $0.4 \mathrm{ml} / \mathrm{min}$ in an isocratic mode found quite well for the detection as well as simultaneous estimation of four drugs. Acquity BEH Phenyl column 
$(50 \mathrm{~mm} \times 2.1 \mathrm{~mm}, 1.7 \mu \mathrm{m})$ with UV detection at $238 \mathrm{~nm}$ was considered best for the separation. The injection volume of $1 \mu 1$ and a column temperature of $30^{\circ}$ were optimized for the study. Standard solutions were prepared and injected six times into the chromatographic system. The evaluated system suitability parameters were tabulated in Table 1. The resolution between two peaks must be greater than 2 . The number of theoretical plates must be more than 2000 and the tailing factor must be less than 2. From the results, it was found that all the parameters were in compliance with the acceptance limits. Hence, these chromatographic conditions were optimized for the estimation of lamivudine, tenofovir disoproxil fumarate, doravirine and efavirenz. A typical UPLC chromatogram from standard preparation was shown in fig. 2.

\section{RESULTS AND DISCUSSION}

The developed reverse phase UPLC method was validated for parameters like specificity, accuracy, linearity, precision, Limit of detection (LOD), limit of quantitation (LOQ) and robustness according to $\mathrm{ICH}$ guidelines $^{[14]}$.

The specificity of the developed method was performed to analyze the interference components which were expected to be present include excipients, degradants and impurities with the analyte peaks during determination of analytes. To establish specificity, sample, blank and the impurities generated by forced degradation were injected into the chromatographic system and observed for any interfering peaks at the RT of analytes. The degradation was carried out intentionally by exposing the samples into various stress conditions. The sample chromatograms were shown in fig. 3. After the injection of sample, blank and degradation samples into the chromatographic system, no interfering peaks were observed at the RT of analytes. Hence, the method was found to be specific for the estimation of drugs.

The precision of the method expresses the closeness of agreement between a series of measurements. It was examined using pure samples. The working standard solutions were prepared and injected six times into the system. The results were tabulated in Table 2. The mean and standard deviation (SD) of peak areas were considered; percentage relative standard deviation (RSD) for peak areas was calculated and reported. RSD values were found within the limits, inferring good repeatability of the developed method.

The linearity was developed between concentration of standard solutions and their responses. The test solutions were prepared from standard solution at six concentration levels from $25 \%$ to $150 \%$ of assay concentration. The obtained peak area versus concentration was treated by the least squares linear regression analysis. The calibration plots were shown

TABLE 1: SYSTEM SUITABILITY

\begin{tabular}{|c|c|c|c|c|}
\hline Analytes & RT $(\min )^{*}$ & Resolution* & Theoretical plates* & Tailing Factor* \\
\hline Lamivudine & $1.013 \pm 0.002$ & - & $3968.7 \pm 251.6$ & $1.11 \pm 0.06$ \\
\hline Tenofovir disoproxil fumarate & $1.236 \pm 0.002$ & $3.45 \pm 0.10$ & $5977.8 \pm 341.4$ & $1.20 \pm 0.03$ \\
\hline Doravirine & $1.430 \pm 0.002$ & $3.00 \pm 0.09$ & $7854.0 \pm 739.2$ & $1.22 \pm 0.06$ \\
\hline Efavirenz & $1.671 \pm 0.003$ & $3.62 \pm 0.12$ & $9716.7 \pm 556.7$ & $1.27 \pm 0.01$ \\
\hline
\end{tabular}

*Each value is a mean of 6 observations \pm standard deviation

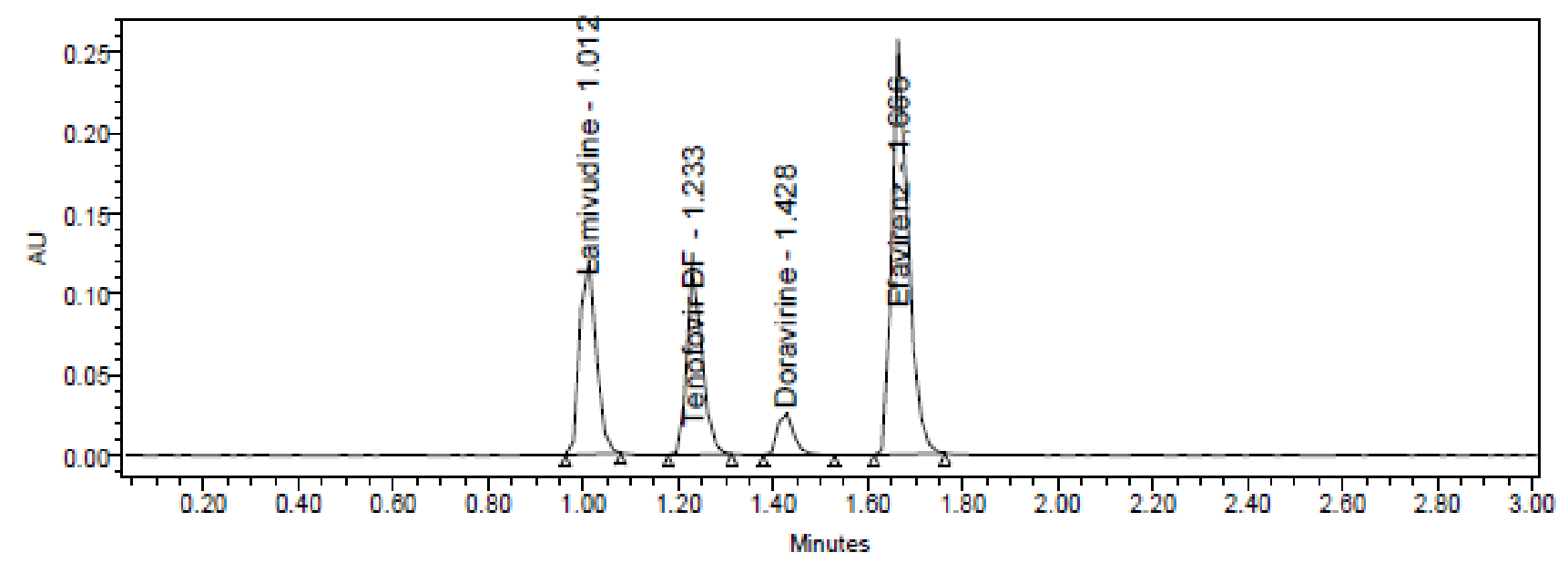

Fig. 2: Chromatogram of standard preparation 


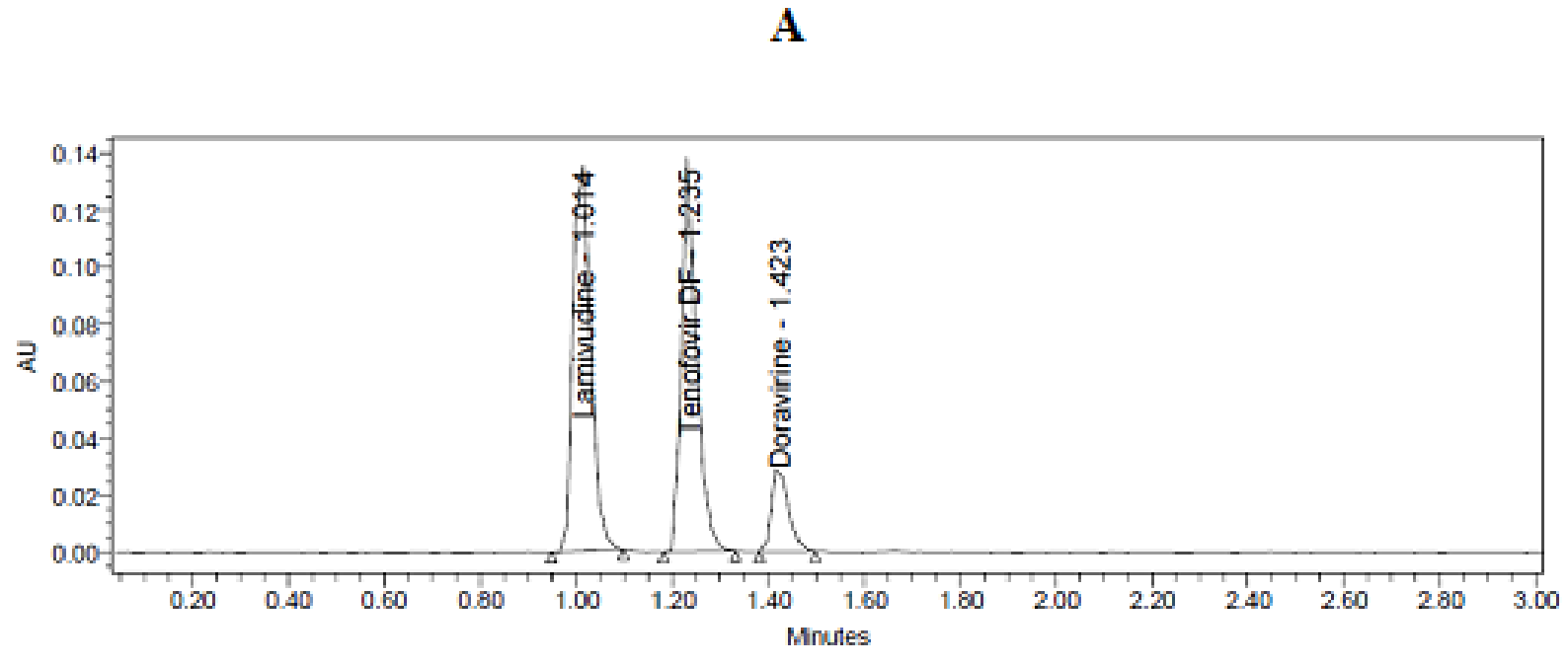

B

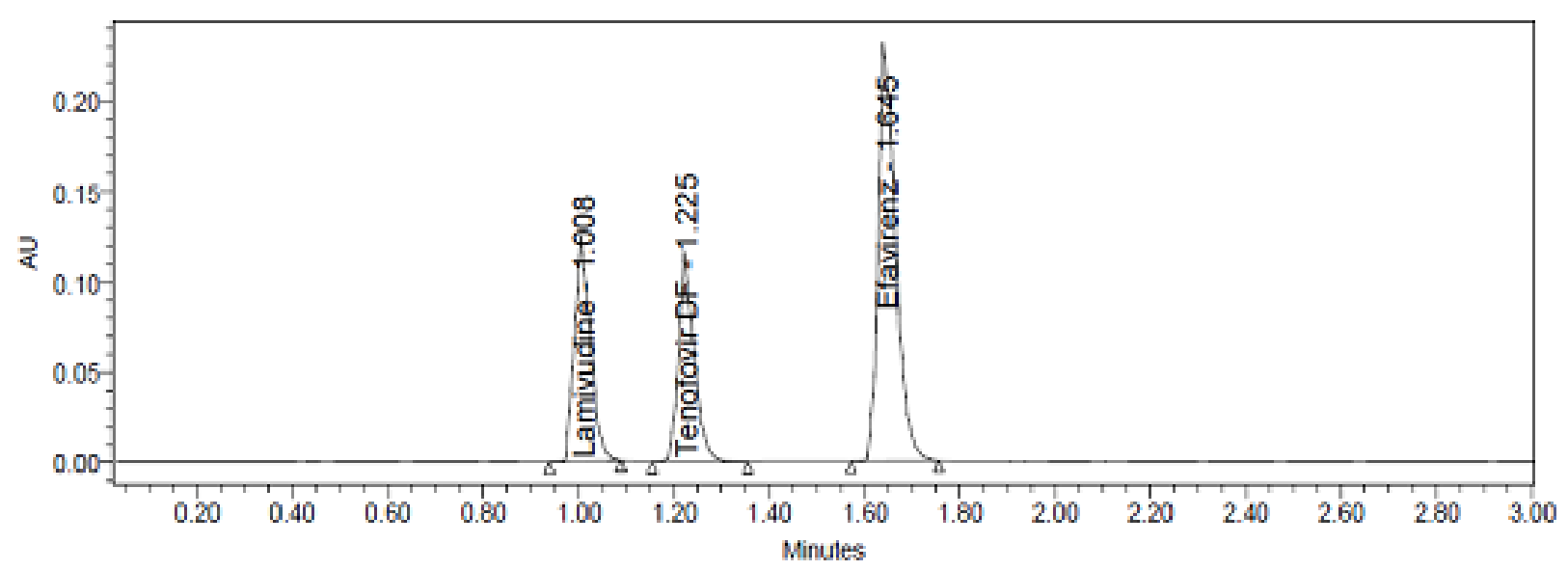

Fig. 3: Chromatograms of sample preparations. Chromatograms of A. Formulation A and B. Formulation B

TABLE 2: RESULTS OF PRECISION STUDIES

\begin{tabular}{|c|c|c|c|c|c|c|c|c|}
\hline \multirow{2}{*}{$\begin{array}{l}\text { No. of } \\
\text { injections }\end{array}$} & \multicolumn{2}{|c|}{ Lamivudine } & \multicolumn{2}{|c|}{$\begin{array}{c}\text { Tenofovir disoproxil } \\
\text { fumarate }\end{array}$} & \multicolumn{2}{|c|}{ Doravirine } & \multicolumn{2}{|c|}{ Efavirenz } \\
\hline & RT (min) & Peak area & RT (min) & Peak area & RT (min) & Peak area & RT (min) & Peak area \\
\hline 1 & 1.009 & 318566 & 1.233 & 301462 & 1.427 & 101594 & 1.666 & 642993 \\
\hline 2 & 1.012 & 312155 & 1.235 & 299482 & 1.428 & 103694 & 1.670 & 645839 \\
\hline 3 & 1.012 & 316678 & 1.236 & 300968 & 1.430 & 102241 & 1.671 & 642575 \\
\hline 4 & 1.013 & 313755 & 1.236 & 298624 & 1.431 & 101216 & 1.672 & 644333 \\
\hline 5 & 1.014 & 315265 & 1.238 & 298743 & 1.432 & 102155 & 1.674 & 645871 \\
\hline 6 & 1.015 & 314625 & 1.238 & 300474 & 1.433 & 101927 & 1.675 & 642637 \\
\hline Mean & & 315174 & & 299959 & & 102138 & & 644041 \\
\hline SD & & 2245.2 & & 1185.8 & & 851.2 & & 1541.8 \\
\hline RSD (\%) & & 0.7 & & 0.4 & & 0.8 & & 0.2 \\
\hline
\end{tabular}

Acceptance criterion is that RSD must be less than $2 \%$

in fig. 4. The results were tabulated in Table 3, which have shown excellent linearity between peak areas and concentration within the specified concentration range. The correlation coefficients were found to be 0.999 for all the four drugs, which met the acceptance criteria and hence the method was said to be linear within the specified concentration range. 
A

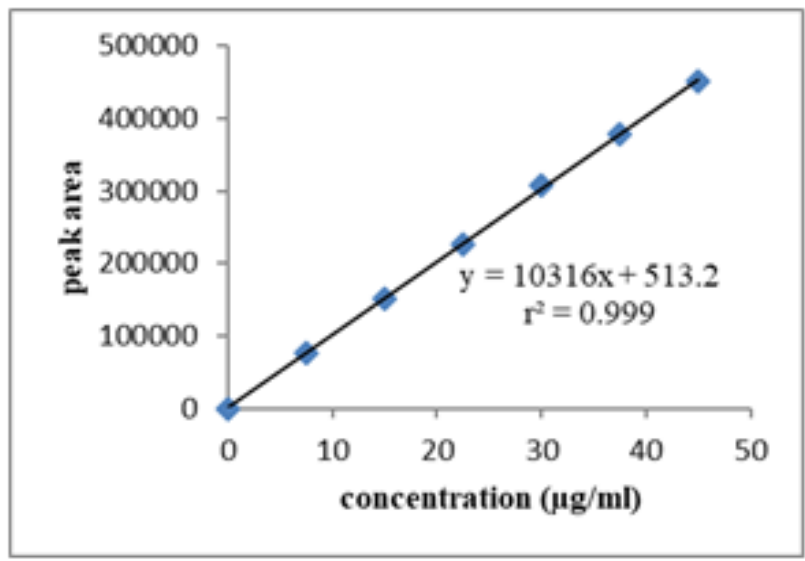

$\mathrm{C}$

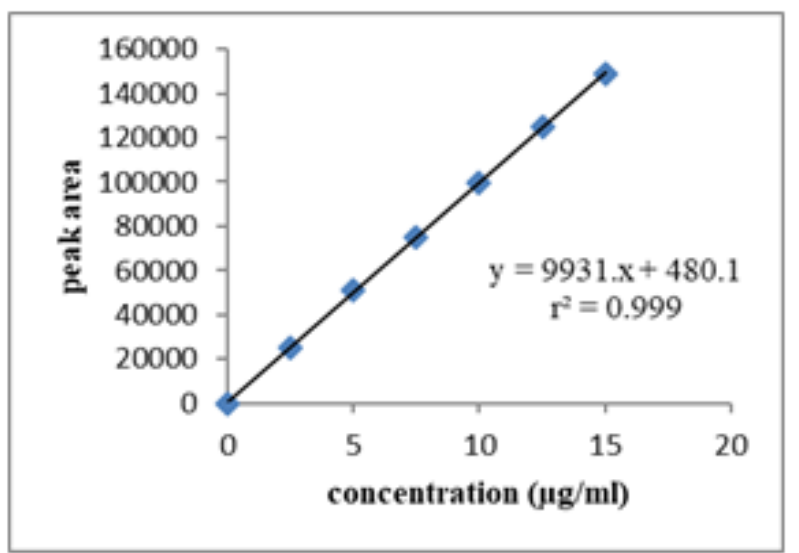

B

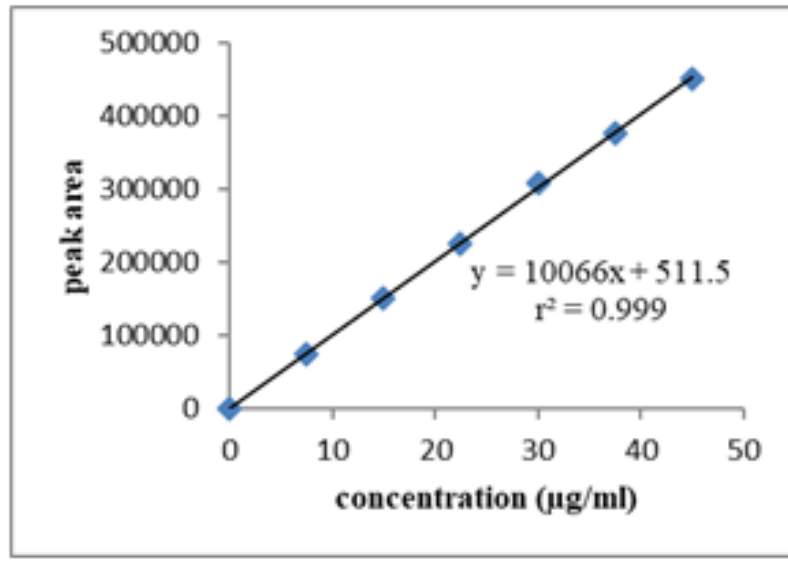

D

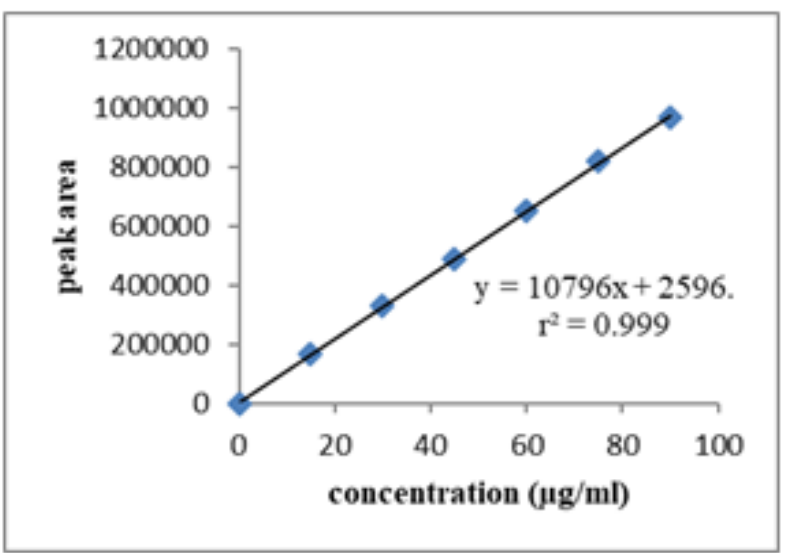

Fig. 4: Calibration plots of analytes. Calibration plots of A. lamivudine, B. tenofovir disoproxil fumarate, C. doravirine and D. efavirenz

TABLE 3: RESULTS OF LINEARITY

\begin{tabular}{|c|c|c|c|c|c|c|c|c|}
\hline \multirow{2}{*}{$\begin{array}{l}\text { Percentage } \\
\text { level }\end{array}$} & \multicolumn{2}{|c|}{ Lamivudine } & \multicolumn{2}{|c|}{$\begin{array}{c}\text { Tenofovir disoproxil } \\
\text { fumarate }\end{array}$} & \multicolumn{2}{|c|}{ Doravirine } & \multicolumn{2}{|c|}{ Efavirenz } \\
\hline & $\begin{array}{c}\text { Concentration } \\
(\mu \mathrm{g} / \mathrm{ml})\end{array}$ & Peak area & $\begin{array}{c}\text { Concentration } \\
(\mu \mathrm{g} / \mathrm{ml})\end{array}$ & $\begin{array}{l}\text { Peak } \\
\text { area }\end{array}$ & $\begin{array}{l}\text { Concentration } \\
\qquad(\mu \mathrm{g} / \mathrm{ml})\end{array}$ & $\begin{array}{l}\text { Peak } \\
\text { area }\end{array}$ & $\begin{array}{c}\text { Concentration } \\
(\mu \mathrm{g} / \mathrm{ml})\end{array}$ & $\begin{array}{l}\text { Peak } \\
\text { area }\end{array}$ \\
\hline 25 & 7.5 & 84266 & 7.5 & 75499 & 2.5 & 25201 & 15 & 164858 \\
\hline 50 & 15 & 154822 & 15 & 150629 & 5 & 50845 & 30 & 328328 \\
\hline 75 & 22.5 & 223455 & 22.5 & 226368 & 7.5 & 74935 & 45 & 488277 \\
\hline 100 & 30 & 311473 & 30 & 308325 & 10 & 99965 & 60 & 650628 \\
\hline 125 & 37.5 & 384776 & 37.5 & 377326 & 12.5 & 124983 & 75 & 818475 \\
\hline 150 & 45 & 469557 & 45 & 450843 & 15 & 148844 & 90 & 968192 \\
\hline $\begin{array}{l}\text { Correlation } \\
\text { coefficient }\left(r^{2}\right)\end{array}$ & \multicolumn{2}{|c|}{0.999} & \multicolumn{2}{|l|}{0.999} & \multicolumn{2}{|l|}{0.999} & \multicolumn{2}{|l|}{0.999} \\
\hline
\end{tabular}

Acceptance criterion is $r^{2}=0.99-1$

The accuracy, also called as trueness, was determined by carrying out recovery studies where known quantities of the drug substance have been added to drug product. The developed analytical procedure has been applied so as to determine the added amount of drug substance. The percent recoveries were calculated and reported. The results of accuracy using formulation $\mathrm{A}$ and $\mathrm{B}$ were presented in Table 4 and Table 5. The results were found within the acceptance criteria which must be in the range of 98-102\%. Hence, the developed method was found to be accurate for the estimation of the mentioned drugs. 
TABLE 4: RESULTS OF ACCURACY (FORMULATION A)

\begin{tabular}{|c|c|c|c|c|}
\hline Analyte & $\begin{array}{c}\text { Accuracy level } \\
(\%)\end{array}$ & $\begin{array}{c}\text { *Amount spiked }(\mu \mathrm{g} / \\
\mathrm{ml})\end{array}$ & $\begin{array}{c}{ }^{*} \text { Amount found }(\mu \mathrm{g} / \\
\mathrm{ml})\end{array}$ & $\begin{array}{c}{ }^{\#} \text { Mean percentage } \\
\text { recovery }\end{array}$ \\
\hline \multirow{4}{*}{ Lamivudine } & 50 & 15 & 15.06 & \multirow{4}{*}{100.40} \\
\hline & 100 & 30 & 30.21 & \\
\hline & 150 & 45 & 45.04 & \\
\hline & 50 & 15 & 14.93 & \\
\hline \multirow[t]{3}{*}{ Tenofovir disoproxil fumarate } & 100 & 30 & 30.26 & \multirow[t]{3}{*}{100.19} \\
\hline & 150 & 45 & 45.07 & \\
\hline & 50 & 5 & 5.03 & \\
\hline \multirow[t]{2}{*}{ Doravirine } & 100 & 10 & 10.00 & \multirow[t]{2}{*}{100.23} \\
\hline & 150 & 15 & 15.02 & \\
\hline
\end{tabular}

*Each value is the mean of 3 observations, "Each value is the mean of 9 observations

TABLE 5: RESULTS OF ACCURACY (FORMULATION B)

\begin{tabular}{|c|c|c|c|c|}
\hline Analyte & $\begin{array}{c}\text { Accuracy level } \\
(\%)\end{array}$ & $\begin{array}{c}\text { *Amount spiked }(\mu \mathrm{g} / \\
\mathrm{ml})\end{array}$ & $\begin{array}{c}\text { *Amount found }(\mu \mathrm{g} / \\
\mathrm{ml})\end{array}$ & $\begin{array}{c}{ }^{\#} \text { Mean percentage } \\
\text { recovery }\end{array}$ \\
\hline \multirow{4}{*}{ Lamivudine } & 50 & 15 & 14.85 & \multirow{4}{*}{99.91} \\
\hline & 100 & 30 & 30.18 & \\
\hline & 150 & 45 & 45.06 & \\
\hline & 50 & 15 & 14.97 & \\
\hline \multirow[t]{3}{*}{ Tenofovir disoproxil fumarate } & 100 & 30 & 30.01 & \multirow[t]{3}{*}{100.01} \\
\hline & 150 & 45 & 45.08 & \\
\hline & 50 & 30 & 30.16 & \\
\hline \multirow[t]{2}{*}{ Efavirenz } & 100 & 60 & 59.35 & \multirow[t]{2}{*}{99.56} \\
\hline & 150 & 90 & 89.28 & \\
\hline
\end{tabular}

*Each value is the mean of 3 observations, "Each value is the mean of 9 observations

The LOD and LOQ specify the lowest amount of analytes that can be detected and necessarily quantified respectively. Several methods were available for determining these limits. Among which, formula method has been applied to determine the limits. The values were calculated using the formulae. $\mathrm{LOD}=3.3$ $\sigma / \mathrm{S}$ and $\mathrm{LOQ}=10 \sigma / \mathrm{S}$, Where, $\sigma$ is the $\mathrm{SD}$ of the $\mathrm{y}$-intercept and $\mathrm{S}$ is the slope of the calibration curves. The detection and quantitation limits were presented in Table 6 . The itemized results showed the sensitivity of the developed method.

Robustness of the analytical method indicates the reliability of the method upon normal usage. It was examined by intentionally altering the chromatographic conditions so as to prove the capability of the method remained unaffected by those variations in chromatographic parameters. The parameters such as flow rate, column temperature, and mobile phase composition were altered to prove the robustness of the developed method. A deviation of $\pm 0.1 \mathrm{ml} / \mathrm{min}$ in the flow rate, $\pm 5^{\circ}$ in the column temperature and $5 \%$ variation in mobile phase ratio were tried individually. A standard solution at test concentration with the specified changes in the operational conditions was injected into the chromatographic system for six times.
The results of robustness were presented in Table 7 . The results infer that all the parameters were found to be within the limits even after slight variations in the chromatographic conditions. Hence, the method was found to be robust.

During the forced degradation study, the standard and degraded samples were injected into the system with a run time of $10 \mathrm{~min}$ and the results were tabulated in Table 8. The percentage of drug degraded in the solution was calculated. The significant degradation was found in the presence of acid and base. Drugs were slightly degraded upon oxidation, under light and heat. The degradation products produced as a result of stress studies did not interfere with the RT of analytes. Therefore, the assay was considered as stability-indicating for the simultaneous estimation of lamivudine, tenofovir disoproxil fumarate, doravirine and efavirenz.

The applicability of the proposed method was confirmed by assaying formulations $\mathrm{A}$ and $\mathrm{B}$. The standard and sample solutions were prepared and injected into the chromatographic system. The amount of drug present in the formulation was calculated and the results were tabulated in Table 9 and Table 10. The results were in 
TABLE 6: RESULTS OF LOD AND LOQ

\begin{tabular}{|c|c|c|c|c|}
\hline Parameter & Lamivudine & Tenofovir disoproxil fumarate & Doravirine & Efavirenz \\
\hline LOD $(\mu \mathrm{g} / \mathrm{ml})$ & 0.15 & 0.10 & 0.04 & 0.32 \\
\hline LOQ $(\mu \mathrm{g} / \mathrm{ml})$ & 0.44 & 0.29 & 0.11 & 0.97 \\
\hline
\end{tabular}

LOD is limit of detection and LOQ is limit of quantitation

TABLE 7: RESULTS OF ROBUSTNESS

\begin{tabular}{|c|c|c|c|c|c|c|c|c|}
\hline \multirow{2}{*}{ Parameter } & \multicolumn{2}{|c|}{ Lamivudine } & \multicolumn{2}{|c|}{$\begin{array}{l}\text { Tenofovir disoproxil } \\
\text { fumarate }\end{array}$} & \multicolumn{2}{|c|}{ Doravirine } & \multicolumn{2}{|c|}{ Efavirenz } \\
\hline & Tailing* & $\begin{array}{l}\text { Plate } \\
\text { count* }^{*}\end{array}$ & Tailing* & $\begin{array}{l}\text { Plate } \\
\text { count* }\end{array}$ & Tailing* & $\begin{array}{l}\text { Plate } \\
\text { count* }\end{array}$ & Tailing* & $\begin{array}{l}\text { Plate } \\
\text { count* }^{*}\end{array}$ \\
\hline $\begin{array}{l}\text { Low flow rate } \\
(0.3 \mathrm{ml} / \mathrm{min})\end{array}$ & 1.16 & 3430.7 & 1.20 & 6147.3 & 1.21 & 8193.2 & 1.25 & 10002.2 \\
\hline $\begin{array}{l}\text { High flow rate } \\
(0.5 \mathrm{ml} / \mathrm{min})\end{array}$ & 1.23 & 4014.0 & 1.17 & 5833.5 & 1.22 & 7280.7 & 1.26 & 8786.7 \\
\hline $\begin{array}{l}\text { Low column } \\
\text { temperature }\left(25^{\circ}\right)\end{array}$ & 1.16 & 3684.8 & 1.17 & 5451.5 & 1.22 & 7491.8 & 1.26 & 9392.0 \\
\hline $\begin{array}{l}\text { High column } \\
\text { temperature }\left(35^{\circ}\right)\end{array}$ & 1.21 & 3586.5 & 1.24 & 5530.7 & 1.18 & 7577.5 & 1.29 & 8995.1 \\
\hline $\begin{array}{l}\text { Low organic phase } \\
(55: 45)\end{array}$ & 1.19 & 3995.5 & 1.21 & 5553.2 & 1.18 & 8271.2 & 1.27 & 10152.8 \\
\hline $\begin{array}{l}\text { High organic phase } \\
(45: 55)\end{array}$ & 1.22 & 3623.3 & 1.18 & 5864.0 & 1.22 & 7468.2 & 1.28 & 8765.0 \\
\hline
\end{tabular}

*Each value is a mean of 6 observations, Acceptance criteria are tailing: <2, plate count: $>2000$

TABLE 8: FORCED DEGRADATION STUDIES

\begin{tabular}{|c|c|c|c|c|}
\hline \multirow{2}{*}{ Stress conditions } & Lamivudine & Tenofovir disoproxil fumarate & Doravirine & Efavirenz \\
\hline & \multicolumn{4}{|c|}{ Percentage Degraded } \\
\hline Acid & 17.37 & 13.54 & 9.55 & 8.31 \\
\hline Base & 12.76 & 15.01 & 3.34 & 6.82 \\
\hline Peroxide & 3.81 & 6.93 & 8.52 & 8.51 \\
\hline Thermal & 2.71 & 1.72 & 2.27 & 3.12 \\
\hline Photolysis & 5.01 & 2.09 & 2.37 & 1.41 \\
\hline
\end{tabular}

TABLE 9: ASSAY RESULTS OF FORMULATION A

\begin{tabular}{lccc}
\hline \multirow{2}{*}{ S. No. } & Lamivudine & $\begin{array}{c}\text { Tenofovir disoproxil } \\
\text { fumarate }\end{array}$ & Doravirine \\
\cline { 2 - 4 } & \multicolumn{3}{c}{ Percentage Assay } \\
\hline 1 & 99.40 & 99.96 & 99.58 \\
2 & 99.28 & 100.25 & 101.33 \\
3 & 99.14 & 99.54 & 100.00 \\
4 & 99.63 & 99.43 & 100.47 \\
5 & 99.65 & 100.24 & 99.52 \\
6 & 100.09 & 99.54 & 101.29 \\
Mean & 99.53 & 99.83 & 100.36 \\
\hline
\end{tabular}

Acceptance criterion is Percentage assay must be $98-102$

conformity with the label claim and hence the developed method can be effectively applied for quality analysis of formulations.

The proposed stability indicating UPLC method was found to be simple, accurate, precise, robust, quick and economic. All the four drugs were eluted within 3 min with good resolution utilizing a simple mobile phase, thereby drastically lessening the analysis time. This method can be used for the assay of drugs in bulk
TABLE 10: ASSAY RESULTS OF FORMULATION B

\begin{tabular}{lccc}
\hline \multirow{2}{*}{ S. No. } & Lamivudine & $\begin{array}{c}\text { Tenofovir } \\
\text { disoproxil fumarate }\end{array}$ & Efavirenz \\
\cline { 2 - 4 } & \multicolumn{3}{c}{ Percentage Assay } \\
\hline 1 & 99.26 & 99.92 & 100.28 \\
2 & 100.32 & 99.20 & 100.07 \\
3 & 99.28 & 100.70 & 99.12 \\
4 & 99.23 & 100.29 & 99.10 \\
5 & 100.25 & 100.29 & 98.97 \\
6 & 100.30 & 99.98 & 99.99 \\
Mean & 99.77 & 100.06 & 99.59 \\
\hline
\end{tabular}

Acceptance criterion is percentage assay must be $98-102$

as well as in their dosage forms either individually or in combinations. Thus, the developed method can be employed for routine assay of bulk and tablets containing lamivudine, tenofovir disoproxil fumarate, doravirine and efavirenz in quality control divisions.

\section{Acknowledgements:}

The author expresses sincere thanks to Spectrum Pharma Research Solutions, Hyderabad for providing necessary facilities to carry out the research work. 


\section{Conflict of Interests:}

The authors declared no conflict of interest.

\section{REFERENCES}

1. Ahmed Z, Shetty SK, Gopinath B, Ahmed M, Sridhar BK. Development and validation of RP-HPLC method for the determination of tenofovir disoproxil in bulk and in pharmaceutical formulation. Int J Chem Sci 2009;7(4):244758.

2. Kandagal PB, Manjunatha DH, Seetharamappa J, Kalanur SS. RP-HPLC method for the determination of tenofovir in pharmaceutical formulations and spiked human plasma. Anal Lett 2008;41(4):561-70.

3. Surve DH, Jindal AB. Development and validation of reversephase high-performance liquid chromatographic (RP-HPLC) method for quantification of efavirenz in efavirenz-enfuvirtide co-loaded polymer-lipid hybrid nanoparticles. J Pharm Biomed Anal 2019;175:1-7.

4. Tejaswi JK, Rajan RG. RP-HPLC method development and validation for simultaneous estimation and forced degradation studies of lamivudine and raltegravir in solid dosage form. Int J App Pharm 2018;10(6):242-8.

5. Rao BV, Vidyadhara S, Nagaraju B, Jhonbi SK. A novel stability indicating RP-HPLC method development and validation for the determination of tenofovir disoproxil fumarate and emtricitabine in bulk and pharmaceutical formulations. Int $\mathrm{J}$ Pharm Sci Res 2017;8(5):2168-76.

6. Zhang LK, Yang R, Sheng H, Helmy R, Zheng J, Cao Y, et al. Characterization of impurities of HIV NNRTI doravirine by UHPLC-high resolution MS and tandem MS analysis. J Mass Spectrom 2016;51(10):959-68.

7. Bhargavi D, Rao BB, Kiran G, Gouthami T, Bakshi V. Method development and validation for related impurities of efavirenz by RP-HPLC Method. Anal Chem Lett 2017;7(5):737-47.

8. Montgomery ER, Edmanson AL, Cook SC, Hovsepian PK. Development and validation of a reverse-phase HPLC method for analysis of efavirenz and its related substances in the drug substance and in a capsule formulation. J Pharm Biomed Anal 2001;25(2):267-84.

9. Srinath A, Sneha B, Alladi A, Ahmed R, Kulkarni RG. Method development and validation for simultaneous estimation of lamivudine, tenofovir and efavirenz in combined tablet dosage form by RP-HPLC and UV-spectroscopic method. Int J Pharm Sci Res 2014;5(12):5491-7.

10. Vanaja P, Anusha N, Giri S. Development and validation of a RP-HPLC method for simultaneous estimation of lamivudine, tenofovir disoproxil fumarate and efavirenz in a combined tablet dosage form. Int J Pharm Pharm Sci 2013;5(3):116-21.

11. Anandakumar K, Abirami G, Murugan S, Ashok B. RP-HPLC method for simultaneous estimation of lamivudine, tenofovir disoproxil fumarate and efavirenz in tablet formulation. J Anal Chem 2013;68(9):815-21.

12. Bhavsar DS, Patel BN, Patel CN. RP-HPLC method for simultaneous estimation of tenofovir disoproxil fumarate, lamivudine, and efavirenz in combined tablet dosage form. Pharm Methods 2012;3(2):73-8.

13. Chengalva $P$, Kuchana $M$. Stability indicating ultraperformance liquid chromatographic method for the simultaneous determination of phenylephrine hydrochloride, chlorpheniramine maleate, paracetamol, guaiphenesin and bromhexine hydrochloride in bulk and pharmaceutical formulation. Int J App Pharm 2019;11(5):284-92.

14. Validation of analytical procedures; Text and methodology ICH Q2 (R1). International conference on harmonization of technical requirements for registration of pharmaceuticals for human use; 2005. 